\title{
Axial forces and bending moments in the loaded rabbit tibia in vivo
}

Janin Reifenrath ${ }^{1 *}$, Daniel Gottschalk², Nina Angrisani ${ }^{1}$, Silke Besdo² and Andrea Meyer-Lindenberg ${ }^{3}$

\begin{abstract}
Background: Different animal models are used as fracture models in orthopaedic research prior to implant use in humans, although biomechanical forces can differ to a great extend between species due to variable anatomic conditions, particularly with regard to the gait. The rabbit is an often used fracture model, but biomechanical data are very rare. The objective of the present study was to measure axial forces, bending moments, and bending axis directly in the rabbit tibia in vivo. The following hypothesis was tested: Axial forces and bending moments in the mid-diaphysis of rabbit tibia differ from other experimental animals or indirectly calculated data.

Methods: A minifixateur system with 4 force sensors was developed and attached to rabbit tibia $(n=4)$, which were subsequently ostectomised. Axial forces, bending moments and bending angles were calculated telemetrically during weight bearing in motion between 6 and 42 days post operation.

Results: Highest single values were $201 \%$ body weight [\% bw] for axial forces and $409 \%$ bw cm for bending moments. Whereas there was a continous decrease in axial forces over time after day $10(P=0.03$ on day 15$)$, a decrease in bending moments was inconsistent $(P=0.03$ on day 27). High values for bending moments were frequently, but not consistently, associated with high values for axial forces.
\end{abstract}

Conclusion: Axial forces in rabbit tibia exceeded axial forces in sheep, and differed from indirectly calculated data. The rabbit is an appropriate fracture model because axial loads and bending moments in rabbit tibia were more closely to human conditions than in sheep tibia as an animal model.

Keywords: Biomechanics, Hind leg, Telemetric, in vivo, Rabbit, Implant research, Tibia

\section{Background}

There are various animal models for musculoskeletal research. Some laboratory species, e.g. mice and rats, are too small for the investigation of implant materials (e.g. orthopaedic plates and screws) in weight-bearing bones. Therefore, in addition to sheep and dogs, rabbits are a commonly used model $[1,2]$. Studies using rabbit tibia were done to assess fracture healing following internal fixation with screws and plates [2,3], external fixation $[4,5]$, and intramedullary nailing [6-8]. Although bone microstructure, bone remodelling, gait, and consequently, the biomechanical forces acting on the bones differ presumably from those of humans, screening of newly developed implant materials is common in animal

\footnotetext{
* Correspondence: janin.reifenrath@tiho-hannover.de

${ }^{1}$ Small Animal Clinic, University of Veterinary Medicine, Bünteweg 9, 30559

Hannover, Germany

Full list of author information is available at the end of the article
}

models. As additional evaluation method, in vivo $\mu$-computed tomography can be performed in rabbits to examine bone and implant alteration during the post operative follow-up period [9]. In contrast, this method cannot be used in larger animals due to their size. To decide, whether the rabbit or a large animal model is the appropriate choice for the aspired research question, knowledge of biomechanical forces is of utmost importance. Especially healing processes and possible implant failure have to be evaluated in dependency on the effective load to convey results to human conditions. Additionally, these data can be used to simulate bone remodelling [10] and to calculate the required stability of implant materials, even during the period of fracture healing, to avoid implant failure in advance.

For sheep, different force data already exists [11-13]. In comparison to calculated loads in human mid diaphysis of the tibia (maximum axial force $420 \%$ body

\section{Biomed Central}


weight [\% bw]) [14], axial forces in sheep tibia were measured much lower (89\% bw [11] and 110\% bw [12]). These discrepancies might be explained with the quadruped gait. In contrast to sheep, the rabbit predominantly loads the hind legs during hopping and therewith approximate two-legged gait. However, there is a paucity of data regarding forces in the rabbit hind leg. An indirect method to calculate developing forces was described [15]. In that study, pins were surgically fixed in the femur, tibia, and metatarsus. Infrared light emitting diodes (LEDs) were attached to the pins, which were detected optically during hopping on a force measurement plate, enabling calculation of the corresponding forces. However, direct measurement methods using external fixateur systems are apparently only described for humans [16,17] and sheep [11-13], but these systems were not small enough to be adapted to the rabbit tibia. A telemetric method for axial force measurement in the rabbit tibia in free physiological movement has been reported [18]. The objective of the present study was telemetric evaluation of in vivo axial forces, bending moments, and bending moment angles in the rabbit tibia with weight bearing in free physiological movement to prove our hypothesis that axial forces and bending moments in the mid-diaphysis of rabbit tibia differ from other experimental animals or indirectly calculated data.

\section{Methods}

Before in vivo measurements were performed, the system was tested in vitro as described for a similar system [18]. To measure axial forces and bending moments in the left tibia of New Zealand White rabbits, a ring fixateur system was designed based on a Smith \& Nephew
3/4 ring fixation system (Figure 1a). The rings at the proximal and distal positions were commercially available $3 / 4$ rings $(50 \mathrm{~mm}$ in diameter; Fa Smith \& Nephew, Marl, Germany). The two rings in the middle, specially designed to fix the force sensors, were aluminium to reduce mass. The two proximal and the two distal rings were consistently joined by two sleeves, threaded rods, and four screw nuts. The proximal and the distal parts were connected by four force sensors (KD24S, $\pm 100 \mathrm{~N}$, Me-Meßsysteme GmbH, Hennigsdorf, Germany) (total weight approximately $250 \mathrm{~g}$ ). The small s-shaped force sensors were oriented parallel to the bone and connected with a measurement amplifier via an associated board (GSV-4BT, Me-Meßsysteme GmbH, Hennigsdorf, Germany). The strain gauge measurement amplifier had a LiPo-battery, four ports, and wireless transmission. A standard Bluetooth dongle was used as a receiver and data were acquired, recorded, and processed using LabView $^{\odot}$ (National instruments Germany $\mathrm{GmbH}$, München, Germany).

Concurrent with force recordings, movement was recorded with a webcam, enabling calculation of the association between measured loadings and movement. Based on Newton's law [19] the axial force $\mathrm{N}$ was calculated as follows:

$$
N=F_{1}+F_{2}+F_{3}+F_{4}
$$

where $\mathrm{F}_{1,2,3,4}$ were the forces measured with the four different force sensors (Figure 1b).

To calculate the bending moment $\mathrm{M}_{\mathrm{b}}$, distances from each sensor to the medial-lateral axis and to the anterior-posterior axis were determined from radiographs.

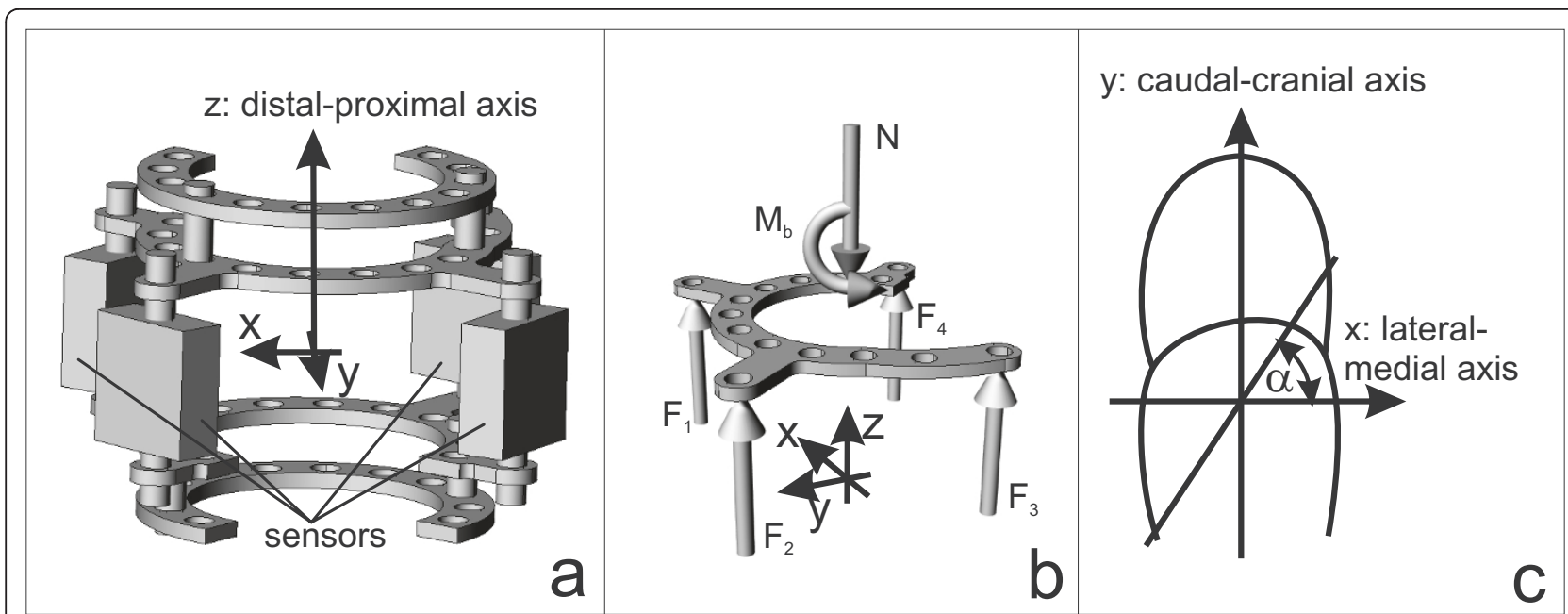

Figure 1 Schematic diagram of the instrumented ring fixateur system. Force sensors were placed between the middle 3/4-rings, enabling measurement of all axial forces between the proximal and distal sections of the ring fixator system (a); schematic diagram for calculation of the axial force $\mathrm{N}$ and bending moment $\mathrm{M}_{\mathbf{b}}(\mathbf{b})$. $\mathrm{F}_{\mathbf{i}}$ were forces measured in the force sensors; Calculation of the angle of the bending axis $(\alpha)$ to the lateral axis $\left(0^{\circ}\right)$ of the left hindleg $(\mathbf{c}) ; x, y, z$ mark the different axes. 
$\mathrm{M}_{\mathrm{x}}$, the moment in the direction of the medial-lateral axis, was calculated as follows:

$$
M_{x}=-a\left(F_{1}+F_{2}\right)+b\left(F_{3}+F_{4}\right)
$$

where $\mathrm{a}$ and $\mathrm{b}$ were the distances of the sensors to the lateral-medial axis. $\mathrm{M}_{\mathrm{y}}$ was the moment in the direction of the anterior-posterior axis and was calculated similar to $\mathrm{M}_{\mathrm{x}}$.

$$
M_{y}=c\left(F_{1}+F_{4}\right)-d\left(F_{2}+F_{3}\right)
$$

where $\mathrm{c}$ and $\mathrm{d}$ were distances between the sensors and the posterior-anterior axis.

The value of the maximum bending moment $\mathrm{M}_{\mathrm{b}}$ was calculated as follows:

$$
M_{b}=\sqrt{M_{x}^{2}+M_{y}^{2}}
$$

The direction $\alpha$ of the bending moment was determined as:

$$
\alpha=\arctan \frac{M_{y}}{M_{x}}
$$

The angle was zero for the medial direction and it is mathematical positive defined (Figure 1c).

The experiment was conducted under a protocol approved by an ethics committee in accordance with German federal welfare legislation (AZ 509.6-42502/307/1304).

Adult female New Zealand White rabbits $(\mathrm{n}=5$, Charles River, Sulzfeld, Germany) were used. Anaesthesia was induced with S-ketamin hydrochloride $(20 \mathrm{mg} /$ $\mathrm{kg}, \mathrm{im})$ and medetomidin $(25 \mathrm{mg} / \mathrm{kg}, \mathrm{im})$ and maintained with isoflurane (2-3 vol.\%) in oxygen mixture (1 $1 /$ min $100 \% \mathrm{O}_{2}$ ). After clipping and routine disinfection of the surgical field, the ring fixateur system was attached to the rabbit tibia. Holes were drilled in the bone and wires $(1.0 \mathrm{~mm}$ in diameter; (Fa Smith \& Nephew, Marl, Germany) were applied (tightened with $30 \mathrm{~N}$ tensile force). Two crossed wires were used in the middle half rings, whereas one wire was used for the proximal and the distal half ring to fix the threaded rods of the fixateur system parallel to the tibia. Before recovery from anaesthesia, radiographs were taken in four planes $\left(0^{\circ}, 45^{\circ}, 90^{\circ}, 315^{\circ}\right)$ and distances between each force sensor and the central axis of the bone were measured.

After an adaption period of 2 weeks, four of the rabbits were anaesthetised and an ostectomy (3-4 mm) of the tibia was performed (Figure 2a). Following the ostectomy and radiographic verification (Figure $2 b$ ), the threaded rods were replaced by force sensors (Figure 2c). Consequently, all developing forces were transferred

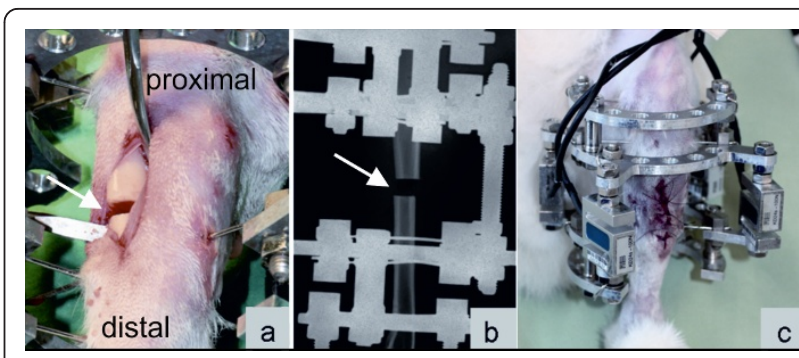

Figure 2 Operative procedure of the rabbit tibia and preparation for measurement. The rabbit tibia was ostectomised to transfer all developing forces via the force sensors: intraoperative picture (a) and post operative radiographic verification (b), ostectomy gap: white arrows; ring fixateur system with four pressure sensors after ostectomy of the tibia directly postoperatively for calibration of the force sensors under general anaesthesia without weight bearing $(\mathbf{c})$

via the sensors [20]. The force sensors were connected (40 cm cables) to a board. Calibration of the force sensors without weight bearing was performed under general anaesthesia. Thereafter, the cables and board were securely wrapped in a bandage to protect them from damage between measurements.

In one rabbit, measurements without ostectomy were performed as control. The calibration procedure and measurement were done as described for the other rabbits. Three measurements were collected daily on 2 days. Mean maximum values and maximum single values of axial forces and bending moments were calculated.

Rabbits were given enrofloxacin $(10 \mathrm{mg} / \mathrm{kg}$, po) daily for $10 \mathrm{~d}$ after surgery. A clinical examination was conducted daily to assess wound healing, swelling, pain, and lameness. For analgesia, meloxicam $(0.15 \mathrm{mg} / \mathrm{kg}$, po) was throughout the entire post operative measurement period, whereas buprenorphine $(0.15 \mathrm{mg} / \mathrm{animal})$ was given for $2 \mathrm{~d}$ post operatively and prior to each measurement to prevent pain-induced reduced weight bearing.

Measurements with weight bearing in motion were conducted $6,8,10,13,15,20$, and $27 \mathrm{~d}$ post operatively (three minutes per measurement, repeated three times each measurement day). In addition, one rabbit was measured at 34 and $41 \mathrm{~d}$ post operatively. During measurements, the measurement amplifier and the LiPo-battery were fixed to the board of the force sensors and attached to a backpack to avoid adding an additional load to the leg. Data recordings were done as described above. During the measurement period, video recording was done to enable association of force and motion data. To calculate the average maximum bending moment for each measurement day, the 10 highest measured values were used. Student's t-test was used to detect differences between measurement days. 


\section{Results}

The ring fixateur system with installed force sensors was small enough to be attached to the rabbit tibia without causing clear visible changes in movement.

Correlating axial forces, bending moments, and bending angles were be recorded during movement with weight bearing (Figure 3), and values were calculated in relation to body weight.

Maximum single values for axial forces were first measured 6 and 8 days post operatively in one and 3 rabbits, respectively (Table 1 ). During physiological movement, a maximum axial force of $201.41 \%$ bw as single value was recorded in Rabbit 4 (the most agile rabbit). Furthermore, an even higher value $(233.68 \%$ bw) was recorded (during capture and restraint) of the same animal on the same measurement day. However, this value was excluded in the following calculations as it was not recorded during physiological movement.

Overall, there was an apparent increase in axial forces between days 6 and 8 (Figure 4), but it was not significant $(P>0.05)$. A continuous decrease in axial forces was apparent after day 10 (first significant at day $15, P=$ 0.03). Based on concurrent assessment of motion and data recording, maximum values for axial forces usually occurred at the beginning of hopping and sometimes during a hopping interval with changing speed.

Single maximum values for bending moments were documented at varying times in individual animals (Table 2) with no consistent decrease which could be observed in the values for axial forces (Figure 5). Significant differences between the time points could only be observed between day 6 and day $27(P=0.03)$. The highest value was documented in rabbit 4 (408.79\% bw $\mathrm{cm})$, which even had the highest values for axial forces.

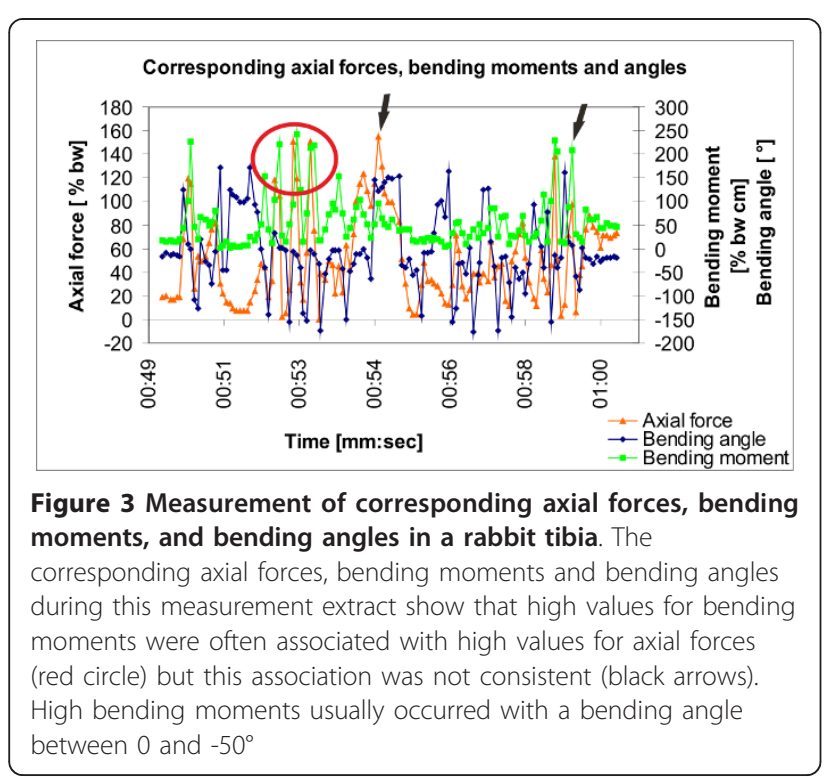

Table 1 Maximum axial forces (single values) of each rabbit with the corresponding measurement day

\begin{tabular}{lllll}
\hline Rabbit & $\begin{array}{l}\text { Force } \\
{[\mathbf{N}]}\end{array}$ & $\begin{array}{l}\text { Body weight } \\
{[\mathbf{k g}]}\end{array}$ & $\begin{array}{l}\text { Force }[\% \\
\text { bw] }\end{array}$ & $\begin{array}{l}\text { Measurement } \\
\text { day }\end{array}$ \\
\hline 1 & -60.32 & 3.98 & 154.54 & 6 \\
\hline 2 & -59.52 & 3.40 & 178.50 & 8 \\
\hline 3 & -54.64 & 3.89 & 143.24 & 8 \\
\hline 4 & -65.77 & 3.33 & 201.41 & 8 \\
\hline Control & -8.09 & 3.50 & 23.57 & \\
\hline
\end{tabular}

In rabbit 3, with $381.24 \%$ bw $\mathrm{cm}$, only a moderate lower maximum value could be measured.

Based on video analysis, maximum values for bending moments occurred at the start of hopping, in some cases during a hopping interval, and additionally when the animal changed the direction, for example in turns. Although, high bending moments corresponded with high axial forces, this did not occur consistently (Figure 3).

Bending angles occurred in all directions. In case of high bending moments, the corresponding bending angles were usually between $-31^{\circ}$ ( 25 percentile) and $3^{\circ}$ (75 percentile), which represented a predominantly mediolateral direction.

Radiographic callus formation with radiopaque structures in the ostectomy gap were first observed 20d post operation with further evidence of healing during the post operative observation period (Figure 6).

\section{Discussion}

For the use of fracture models in orthopaedic research, knowledge of developing forces is of utmost importance

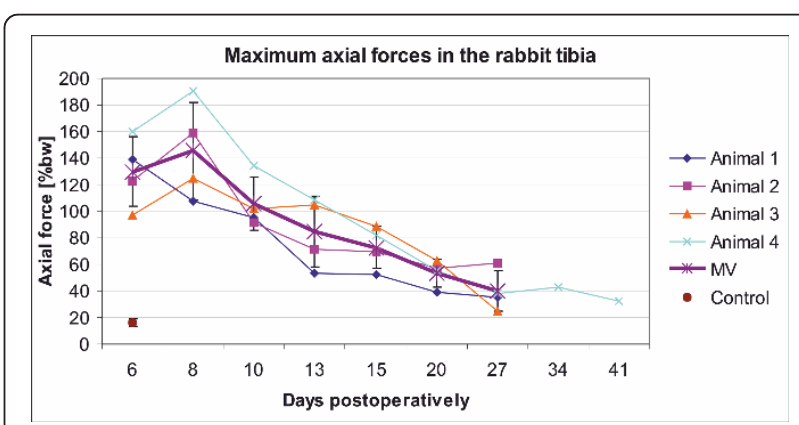

Figure 4 The progress of developing maximum axial forces during the postoperative observation interval. Measurements were performed until day 27 and in one rabbit additionally at day 34 and day 41, in comparison to a control animal without ostectomy (brown spot). A continous decrease in axial forces was apparent after day 8 . The mean value of the ten maximum values of each measurement day were calculated for each animal (animal 1 to 4 ) and summarised for all animals (MV, stars). The ten maximum values were single measurement points, derived from the three measurement periods of the day. 
Table 2 Maximum bending moments (single values) of each rabbit with the corresponding measurement day

\begin{tabular}{lllll}
\hline Rabbit & $\begin{array}{l}\text { Bending moment } \\
{[\mathbf{N ~ c m}]}\end{array}$ & Body weight $[\mathbf{k g}]$ & $\begin{array}{l}\text { Bending moment } \\
{[\% \text { bw cm] }}\end{array}$ & Measurement day \\
\hline 1 & 80.110 & 3.98 & 205.25 & 6 \\
\hline 2 & 127.11 & 3.40 & 381.24 & 8 \\
\hline 3 & 105.18 & 3.89 & 275.72 & 15 \\
\hline Control & 133.50 & 3.33 & 408.80 & 8 \\
\hline
\end{tabular}

to compare mechanical loading with the situation in humans and to simulate bone remodelling [10] and the required stability of implant materials, even during the period of fracture healing.

Although the rabbit is a well-established animal model for orthopaedic research, apparently only indirect calculations of forces in the hind leg of this species have been reported [15]. Unfortunately, the rabbit hind leg is too small for direct methods of measurement as done in humans [16,17] and sheep [12,13]. In the present study, a new method for telemetric measurement of bending moments, bending angles and axial forces in the rabbit tibia with a very good clinical tolerance was developed.

The measured mean axial forces in the rabbit tibia with weight bearing in movement reached up to $201 \%$ bw. In previous studies, where axial forces without bending moments were measured [18], mean axial forces reached $152 \%$ bw. Furthermore, even higher axial forces $(548 \% \mathrm{bw})$ were calculated for the tarsal joint of rabbits [15]. However these forces were indirectly calculated and additionally could be quite different from forces in the mid-diaphysis of the tibia, due to the effects of muscles and tendons. In comparison to calculated loads in human mid diaphysis of the tibia

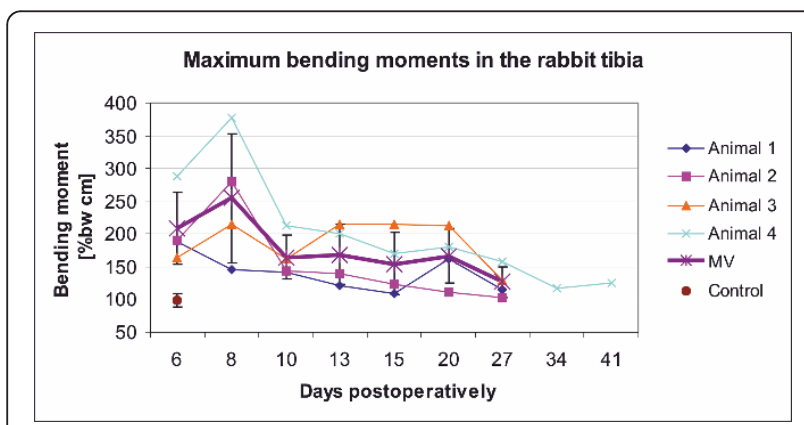

Figure 5 The progress of developing maximum bending moments during the postoperative observation period. Maximum bending moments of 27 and in one animal 41 days are shown in comparison to a control animal without ostectomy (brown spot). The mean value of the ten maximum values of each measurement day were calculated for each animal (animal 1 to 4) and summarised for all animals (MV, stars). The ten maximum values were single measurement points, extracted from the three

measurement periods of the day. (maximum axial force $420 \%$ bw) [14] rabbits seem to reach more comparable loads in the mid diaphysis than sheep (measured axial forces of $89 \%$ bw [11] and $110 \%$ bw [12]). Perhaps the predominant load of the hind legs during hopping might have caused these discrepancies to the sheep.

The maximum bending moment in rabbit tibia in this study was $409 \%$ bw $\mathrm{cm}$ and thereby almost reached bending moments in human tibia (maximum bending moment in mid diaphysis up to $562 \% \mathrm{bw} \mathrm{cm}$, calculated from the results of Wehner et al. [14]). In the rabbit hind leg, bending moments mainly occurred in a medial-lateral direction and much less often in an anterior-posterior direction. In a sheep model telemetrically measured bending moments in anterior-posterior direction were between 50 and 100 $\mathrm{cm}$ kilopond (which match 50 to $100 \mathrm{~kg} \mathrm{~cm}$ ) for female sheep with a body weight of 50-55 kg [21]; this corresponded to an approximate value of $100-200 \% \mathrm{bw} \mathrm{cm}$, but bending moments in medial-lateral were not considered [21]. Another theoretical calculation exists, where bending moments up to $39 \mathrm{Nm}$ are evaluated during the stem phase [22]. With an assumed body weight of $50 \mathrm{~kg}$, this value equates to $780 \% \mathrm{bw} \mathrm{cm}$ and therewith is much higher than the telemetric measured value in the in vivo study [21]. It is even higher than the measured values for the rabbit in our study. However a theoretical calculation can differ from measured results in vivo.

A decrease in axial forces and bending moments during the post operative observation period is caused by callus formation in the ostectomy gap. Consequently occurring forces only partially were transferred via the force sensors, depending on the callus stiffness. It is noteworthy that the axial force constantly decreased whereas no decrease in bending moments was detected. Fibrous tissue and beginning osseous callus formation in the ostectomy gap better bear up against axial forces than bending moments.

It is also noteworthy that allowing free movement, including changes in directions, provides a more comprehensive assessment of bending moments than measurements obtained with animals on treadmills, which are restricted to movement in only a single consistent direction. However, a possible influence of the mass of inertia of the system on the measurements during 

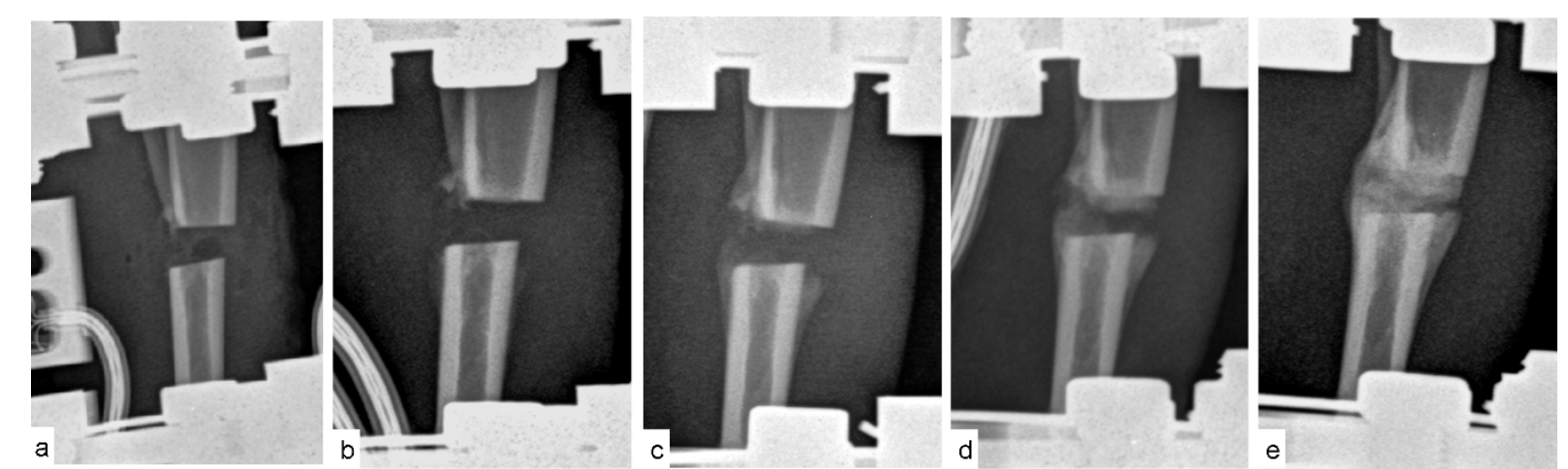

Figure 6 Radiographic control of the ostectomy gap in Rabbit 4. Callus formation was evaluated post operatively with radiographic pictures (medial-lateral view); the ostectomy gap is shown immediately post operatively (a), 13 (b), 20 (c), 27 (d) and 42 days post operatively. Radiopaque structures in the ostectomy gap were first detected 20 days post operatively and increased until day 42

movements with acceleration cannot be excluded. In the moment of the maximum force during hopping, the system is accelerated in the opposite direction. Thus, the measured forces might be slightly lower than the real forces.

Nevertheless, our hypothesis was supported; axial forces in rabbit tibia exceeded axial forces in other experimental animals and differed from indirectly calculated data. For this reason, the rabbit is an appropriate animal model for fracture repair in orthopaedic research regarding the axial forces. Bending moments in rabbits even reached similar values than calculated data in human mid diaphysis of the tibia.

Thus, the rabbit is actually better qualified than the sheep because implants with adequate mechanical stability in sheep might fail in humans due to higher axial forces. A limitation for the use of rabbits is the animal size (evaluation of complex implant geometries is impossible) and a different histological bone structure [23], so that healing properties might be different.

\section{Conclusion}

Compared to sheep, axial forces and bending moments in the rabbit tibia more approach axial forces and bending moments in humans. However, an entire comparison of bending moments between sheep, human and rabbit remains difficult due to incomplete directly measured data for bending moments in human and sheep. In conclusion, the rabbit is an appropriate animal model for fracture repair with simple implant geometries, especially due to its easy handling and the feasibility of additional examination methods like in vivo $\mu$-computed tomography.

\section{Acknowledgements}

This study is part of the collaborative research centre 599, which is sponsored by the German Research Foundation (DFG).

\section{Author details}

${ }^{1}$ Small Animal Clinic, University of Veterinary Medicine, Bünteweg 9, 30559 Hannover, Germany. ${ }^{2}$ Institute of Continuum Mechanics, Appelstraße 11, 30167, Hannover, Germany. ${ }^{3}$ Clinic for small animal surgery and reproduction, centre of clinical veterinary medicine, Faculty of Veterinary Medicine Ludwig-Maximilians-Universität München, Veterinärstr. 13, 80539, Munich, Germany.

\section{Authors' contributions}

$J R$ carried out the study design, the animal measurements with data acquisition and drafted the manuscript. DG carried out the development of the measurement system and the calculation of data. NA participated in the animal measurements and data collection. SB participated in the design of the study, the measurement system and data calculation and helped to draft the manuscript. AML supervised the study, participated in its design and coordination and performed the operation procedure. All authors read and approved the final manuscript.

\section{Competing interests}

The authors declare that they have no competing interests.

Received: 21 December 2011 Accepted: 30 March 2012

Published: 30 March 2012

\section{References}

1. An YH, Friedman RJ: Animal models in orthopaedic research CRC Press: Boca Raton; 1998

2. Albanese SA, Spadaro JA, Chase SE, Geel CW: Bone growth after osteotomy and internal fixation in young rabbits. J Orthop Res 1996, 14:921-926.

3. Böstman $\mathrm{O}$, Päivärinta U, Partio $\mathrm{E}$, Vasenius J, Manninen $\mathrm{M}$, Rokkanen P: Degradation and tissue replacement of an absorbable polyglycolide screw in the fixation of rabbit femoral osteotomies. J Bone Joint Surg Am 1992, 74:1021-1031.

4. Terjesen T, Johnson E: Effects of fixation stiffness on fracture healing. External fixation of tibial osteotomy in the rabbit. Acta Orthop Scand 1986, 57:146-148.

5. Aalto K, Holmstrom T, Karaharju E, Joukainen J, Paavolainen P, Slatis P: Fracture repair during external fixation. Acta Orthop Scand 1987, 58:66-70.

6. Kaartinen E, Paavolainen P, Holmstrom T, Slatis P, Happonen RP: Different healing patterns of experimental osteotomies treated by intramedullary nailing. Arch Orthop Trauma Surg 1993, 112:171-174.

7. Ellsasser JC, Moyer CF, Lesker PA, Simmons DJ: Improved healing of experimental long bone fractures in rabbits by delayed internal fixation. J Trauma 1975, 15:869-876.

8. Worlock P, Slack R, Harvey L, Mawhinney R: The prevention of infection in open fractures. An experimental study of the effect of antibiotic therapy. J Bone Joint Surg Am 1988, 70:1341-1347. 
9. Huehnerschulte TA, Angrisani N, Rittershaus D, Bormann D, Windhagen H, Meyer-Lindenberg A: In vivo corrosion of two novel magnesium alloys ZEK100 and AX30 and their mechanical suitability as biodegradable implants. Materials 2011, 4:1144-1167.

10. Besdo S: Determination of dynamically adapting anisotropic material properties of bone under cyclic loading. J Biomech 2011, 44:272-276.

11. Heller MO, Duda GN, Ehrig RM, Schell H, Seebeck P, Taylor RW: Musculoskeletal loading in the sheep hind limb: Mechanical boundary conditions for healing [in German]. Mat.-wiss. u. Werkstofftech 2005, 36:775-780.

12. Grasa J, Gómez-Benito MJ, González-Torres LA, Asiaín D, Quero F, GarcíaAznar JM: Monitoring in vivo load transmission through an external fixator. Ann Biomed Eng 2010, 38:605-612.

13. Mora G, Forriol F: Mechanical analysis of the healing of different osteotomies fixed externally. Int Orthop 2000, 24:295-298.

14. Wehner T, Claes L, Simon U: Internal loads in the human tibia during gait. Clin Biomech (Bristol, Avon) 2009, 24:299-302.

15. Gushue DL, Houck J, Lerner AL: Rabbit knee joint biomechanics: motion analysis and modeling of forces during hopping. J Orthop Res 2005, 23:735-742.

16. Taylor WR, Heller MO, Bergmann G, Duda GN: Tibio-femoral loading during human gait and stair climbing. J Orthop Res 2004, 22:625-632.

17. Seide $K$, Weinrich $N$, Wenzl ME, Wolter $D$, Jürgens $C$ : Three-dimensional load measurements in an external fixator. J Biomech 2004, 37:1361-1369.

18. Flörkemeyer $\mathrm{T}$, et al: Telemetric in vivo measurement of compressive forces during consolidation in a rabbit model. Techn Health Care 2011, 19:173-183.

19. Gross D, Hauger W, Schröder J: Wall WA: Statik. 10 edition. Heidelberg, Berlin: Springer; 2008.

20. Claes LE, Cunningham JL: Monitoring the mechanical properties of healing bone. Clin Orthop Relat Res 2009, 467:1964-1971.

21. Cordey J, Schnetzer M, Brennwald J, Regazzoni P, Perren SM: Direct in vivo Measurements of Torque and Bending in Sheep Tibiae. In Current Concepts of Internal Fixation of Fractures. Edited by: Cordey J, Schnetzer M, Brennwald J, Regazzoni P, Perren SM. Berlin, New York. Springer Verlag; 1980:

22. Hutzschenreuter PO, Sekler E, Faust G: Loads on muscles, tendons and bones in the hind extremeties of sheep - A theoretical study. Anat Histol Embryol 1993, 22:67-82.

23. Pearce Al, Richards RG, Milz S, Schneider E, Pearce SG: Animal models for implant biomaterial research in bone: a review. Eur Cell Mater 2007, 13:1-10.

doi:10.1186/1751-0147-54-21

Cite this article as: Reifenrath et al: Axial forces and bending moments in the loaded rabbit tibia in vivo. Acta Veterinaria Scandinavica 2012 54:21.

\section{Submit your next manuscript to BioMed Central and take full advantage of:}

- Convenient online submission

- Thorough peer review

- No space constraints or color figure charges

- Immediate publication on acceptance

- Inclusion in PubMed, CAS, Scopus and Google Scholar

- Research which is freely available for redistribution

Submit your manuscript at www.biomedcentral.com/submit
Biomed Central 